\title{
Gender Divergence in Physical Education Classes ${ }^{1}$
}

\author{
Fernando Luiz Cardoso ${ }^{2}$ \\ Maura Lúcia Felipe \\ Universidade do Estado de Santa Catarina \\ Claus Hedegaard \\ Université du Maine
}

\begin{abstract}
We evaluate a group of students, presumed by their physical education teachers to be gender divergent. This study suggests that PE teachers confuse "gender-divergence" with uncoordinated motor behaviors. This may be because PE classes emphasize motor abilities and coordination and PE teachers may pay particular attention to these characteristics and use them (wrongly) as a criterion for gender divergence. However, the 10 presumed "divergent students" differ from their peers by being more likely to have friends of the opposite sex, interacting with groups of the opposite sex, preferring physical activities typical of the opposite sex, demonstrating less knowledge of sex, preferring interactive rather than collaborative activities and preferring more individual, less complex, less aggressive activities with less body contact.
\end{abstract}

Key words: gender identity; gender role; motor orientation; sportive orientation.

\section{Divergência de Gênero em Turmas de Educação Física}

\begin{abstract}
RESUMO - Avaliou-se um grupo de estudantes previamente indicados pelos seus professores de Educação Física como sendo "divergentes" em termos de identidade de gênero. Este estudo sugere que os professores confundem divergência de gênero com comportamento motor descoordenado. Isto talvez se deva porque estes enfatizem demais as habilidades motoras estandartes e as utilizem de forma equivocada como um critério para avaliar divergência da identidade de gênero. No entanto, os 10 estudantes previamente indicados como divergentes em relação aos colegas do mesmo sexo, têm mais amigos do sexo oposto, interagem mais com grupos do sexo oposto, preferem atividades físicas típicas do sexo oposto, demonstram menos conhecimento sobre sexo e preferem atividades individuais às coletivas, atividades menos complexas, menos agressivas e com menor embate corporal.
\end{abstract}

Palavras-chave: identidade de gênero; papel de gênero; orientação motora; orientação esportiva.

Gender-role stereotyping is well-documented in schools (Cardoso, 1994a; Frasher \& Walker, 1972; Jackson, 1968; Levy \& Stacey, 1973; Lynch, 1975; Reha \& Nappi, 1975; Romero, 1994; Saario, Jacklin \& Tittle, 1973) and the social conflict that may result from atypical gender behavior, is usually perceived as problematic by educators, especially in physical education classes. This type of conflict has inspired a series of studies of male children with conflictive sexual identity during the past decades (Blanchard, Dickey \& Jones, 1995; Davenport, 1986; Green, 1974, 1976, 1987; Green, Williams \& Goodman, 1985; Grellert, Newcomb \& Bentler, 1982; Hockenberry \& Billingham, 1987; Whitam, 1983, 1991; Whitam \& Mathy, 1986; Zucker, 1990; Zucker \& Bailey, 1995). These boys are commonly teased and called "sissies" by their peers because they act like "girls" and have gestures and mannerisms considered feminine.

Often divergent children are bullied, creating additional problems for the victims, for the bullies and for their adult

1 We would like to thank the participants in this research, who must remain anonymous, but without whom this study would not have been possible. Dr. Dennis Werner kindly gave valuable advice during the study and preparation of the manuscript. FLC expresses his gratitude to CAPES (Brazil) for financing his Ph.D. in the United States. studies.

2 Endereço: Rua Benevenuta Bartlet James, 69, Florianópolis, SC, Brasil 88015-630.E-mail:d2flc@udesc.br caretakers. Despite these problems, studies of the inclusion of gender-divergent children in school activities have been rare. In a review of 982 manuscripts published in the major journals of sports and exercise in USA between 1987 and 2000 , only $1,22 \%$ included references to sexual orientation (Duda \& Alison, 1990). We need to understand better exactly where the differences between gender-divergent and other children lie. To what extent are these differences due to differences in motor behavior, psychological preferences or gender identities.

Bates, Bentler and Thompson (1979) illustrated the androgynous motor behavior of gender divergent boys, but only Green, Neuberg, and Finch (1983) compared the motor behavior of these boys with conventional boys and girls. They concluded that the "feminine" boys occupied an intermediate position in motor behavior, one that was neither distinctly "feminine" nor distinctly "masculine."

In the present study we investigated gender-divergent children's motor behavior in order to determine whether particular motor patterns were important for the perception of an individual as "gender divergent". We evaluated a group of students, pointed out as gender divergent by their physical education teachers. Most of the teachers interviewed, labeled these students as having some kind of "divergent gender identity" and approached this conflict in terms of moral 


\section{F. L. Cardoso e cols.}

values. Gender divergent students for them were boys more or less "effeminate", more or less "abnormal," more or less "awkward," or more or less "wrong."

We paid particular attention to the social interactions of these children and their stated preferences for social interaction. We wanted to determine if the supposedly gender divergent students differed from their supposedly "gender typical" peers, and whether the teachers' emic determination of gender divergence was based on characteristics common to the indicated students. We designated the students as "gender divergent" rather than androgynous, because the teachers explicitly referred to their unusual gender expressions, but the participants were not subjected to a formal test of gender divergence. The term "androgyny" generally refers to intermediate scores on femininity and masculinity scales (Donelson \& Gullahorn, 1977; Wakefield, Sasek, Friedman \& Bowden, 1976). But in this study the gender-divergent individuals may have had just one prominent characteristic associated by the teacher with the other gender.

Physical education (PE) classes are an excellent setting to investigate social interactions, because they have a different structure from other classes at school, yet are similar in educational systems around the world. PE classes are structured for everybody to participate simultaneously, rather than sequentially, and they rely far more on interaction than do other classes.

Usually gender divergence among boys receives more attention. But "tomboys" (masculine girls) are not rare in school settings. Donelson and Gullahorn (1977) and Hemmer and Kleiber (1981) showed that "tomboys" are quite common although less likely to be seen as "abnormal."

In most Brazilian educational systems, after the 4th year of elementary school, PE classes are taught separately for boys and girls. Although many efforts have been made to change the gender segregation, coeducational PE classes are absent from most Brazilian schools. Nevertheless, Brazilian PE classes rely on the same strategy as PE classes in other industrialized nations, and emphasize team sports and alternating technically and physically demanding activities.

\section{Method}

\section{Participants}

We studied a sample of 20 students from the classes of six Brazilian PE teachers in two different public schools, who agreed to take part in this project. During an official meeting with the PE instructors, they spontaneously indicated that they had confronted gender divergence in class, and were concerned about the issue. The students were from 9 to 14 years old, and presumed to be either gender divergent or gender typical by their respective PE teachers. The six PE teachers interviewed (three male and three female) ranged from 34 to 41 years old and had been teaching for an average of 15 years. Two of the teachers taught male, female, and coeducational classes; only one taught exclusively male classes. Previously in their careers, one had worked only with male classes, one had worked with male and female classes, and four had worked with all kinds of PE classes. Independent of their assignment, most of them also worked with coeducational PE classes, and thus all had the opportunity to experience the conflicts between genders in PE classes.

\section{Measures}

To avoid the researchers' ethnocentric perceptions, we use the anthropological strategy of working with "emic" samples. An "emic" interpretation of cultural events is one that is subjective and defined by the native informants (Harris, 1968), in this case the perception of teachers in two Brazilian public schools. That is, we did not use our etic (researcher defined) categories of gender roles in the sampling process nor in our subsequent classification of individuals.

We did not attempt to assess the "correct" view of school behavior. Instead, we attempted to identify, through observational research, characteristics that might clarify the basis of teachers' identification of some students as "gender divergent." In our observations we focused on differences between the gender-divergent and non-divergent children with regard to motor behaviors, and social interactions with peers and teachers. In short, we wished to examine if the local perception of gender divergent behavior (emic categories) in Brazilian schools, corresponded to observational differences (etic categories) found in similar settings (PE classes) elsewhere. We will relate our etic categories to the teachers' emic categories in the results section of the paper. This methodology is rare in both anthropology (where emic categories are described without attempts to relate them to etic categories) and sociology (where etic categories are used with little regard for the categorizations of those being studied). We believe that this strategy, which allows explicit comparison to other studies, should be encouraged in all the social sciences.

\section{Procedures}

Ten gender divergent students were identified by their teachers prior to this study - one was female, nine were male. With the teachers' and schools' informed consent the gender divergent individuals were first observed discreetly during two weekly physical education classes for approximately one month. The observations permitted a codification of the gender divergent students' interactions with other students. Then, at the request of the researchers, the teachers introduced us to their physical education classes, and asked for their students' collaboration with this study. Following the introduction, the researchers told the class that 20 students would be selected "randomly" to be interviewed. Ten students were in fact selected at random. The other 10 only appeared to be selected randomly; this group consisted of the students identified earlier as gender divergent by their teachers. We used this strategy so as not to expose the indicated students to their peers. Because of our desire to protect the divergent students and of the informal research techniques utilized, we did not ask for official parental consent. But we had official school consent and support, as well as, the students' spontaneous participation. At the time of this study ethical commissions had not yet been created at the university. 
To assess the students' socialization with their classmates, we asked them the following questions based on the most common social conflicts that result from gender divergent behavior and the influence of these conflicts on gender divergent children during class:

1. Do you like your classmates?

2. Who is your best friend? Is a male or a female your best classmate?

3. Which games do you like to play?

4. Which sports do you like the most?

5. With whom do you prefer to play? Boys or girls?

These questions relate to the students' social behavior, and the answers reflect the students own perceptions of issues that correspond to observations made during the PE classes. Question 1 reflects the students' own view of their social situation, and whether they are integrated in the social structure - this corresponds to our observations of their interaction with peers during PE classes. Questions 2 and 5 reveal whether the students interact more with members of their own or the other sex - this corresponds to our observations of their interaction with peers of either sex during PE classes. Questions 3 and 4 reveal the personal preferences of the participants. We summarize these into preferences for solitary, interactive, or collaborative activities, which allowed us to verify whether the indicated participants like or dislike sports.

In addition, to identifying if there is any difference between the gender divergent participants and their peers with respect to information about sexual education, we asked them whether they knew what human sexuality is, and we were careful to avoid being suggestive or otherwise embarrassing the students.

To complement our observations of the students' behavior and our interviews with them, we also carried out semistructured interviews with the six PE teachers. Other teachers also had similar concerns and experiences with this issue, but declined to take part because they thought it would impose on the privacy of their pupils.

\section{Results}

\section{Observations of gender divergent students during PE class}

Student 1 is a pre-adolescent boy. He has generally good relationships with his peers in class, and is cheerful and extrovert. He does not like to do any of the activities assigned to the boys in his PE class, and, whenever possible he runs to play with two of his female peers in another playground. He shows the same behavior in all observed classes. He has pronounced body movements, characteristic of females. $\mathrm{He}$ not only swings his arms to the sides, but also waves his arms in the air with free and gentle movements of his hands. He likes to play tag with his female peers, and is usually quite creative and motivated to play with the girls. He usually stays away from the other boys, who tease and bully him. He seems to be stigmatized by his male peers.

Student 2 was observed during soccer classes, where he constantly sought interaction with the group. In addition, he often talked to his classmates and acted as a member of the group. He has knock-knees and difficulty coordinating his leg movements. This physical condition gives him a clumsy walking and running pattern. Furthermore, he also has an unusual chest with oversized breasts tissue and other difficulties in general body coordination. He appears to be slightly disabled. Due to his unskillful behavior, which might trouble his class's team, he did not take part in the games at the school championship. Unlike the other gender divergent students, this student felt very motivated when the teacher pushed or stimulated him to repeat attempts. Despite his bodily limitations, he enjoyed taking part in the PE class activities.

Student 3 was observed during volleyball classes where he displayed a good relationship with his classmates. His body language was accentuated by more "light arm" movements compared to others; for example his ball receiving was usually carried out in a typically girlish manner with limp wrists. He moved in a very careless way, as if trying to show his lack of interest in the PE class and he had a sharp vocal tone. Nevertheless, he seemed rather extrovert and was aware of all the class activities. We also noticed that this student tried to stay close to the PE teacher and always tried to attract his attention. Despite our attempts to be discreet, he made considerable efforts to figure out who we were, and was constantly aware of the entire PE class environment.

Student 4 was also observed during the volleyball classes. His body movements resembled those of other boys in his class with good coordination. He mixed very little with his peers, and was excluded by the others from group activities in the class. This student demonstrated difficulties with volleyball gestures due to his lack of skill in terms of visual perception and hand coordination. Because of these limitations, he made no technical contribution to the volleyball game, which requires relaxation of the hand muscles and a subsequent contraction to accomplish the ball reception. He kept quiet most of the time, and appeared to be a very introvert individual.

Student 5 was observed during handball classes, where he showed behavior that was noticeably different from that of his male peers. Whenever possible, he moved far away from his peers. During warm-up, he ran with strong contracted movements and he showed a great concern for his own clothes. During class, he looked uncomfortable in his PE uniform, often pulling his pants up and his shirt down in order to make himself more comfortable. Frequently, he put his fingers in his mouth, and gnawed his fingernails as if anxious. He glanced distrustfully around to assure himself that nobody was observing him. He gave the impression that he was worried about the observers' presence during the first few days, although he forgot about us later on. The last day of observation, he approached us to ask about the time. When he had to participate in the collective game, he avoided touching the ball. In short, he did not relax in class, and his discomfort was evident when he had to participate in PE classes.

Student 6 was observed in recreational classes, where the main activities were a PE program for the first years of school (1st to 4 th). His participation was apathetic. He expressed no enthusiasm when taking part in the games and he was very quiet most of the time. According to his teachers' and peers' 
he is "odd" since he does not present the same energy that the others boys do in class, and according to his peers, "he resembles a girl."

Student 7 was the only girl included in this study. She was very extrovert and self-confident in her social interaction as well as in her body skill coordination. She was very communicative and willing to participate in any activity, however her peers and the teacher complained that she was quite brusque and had a rude way of participating in the activities. She differed from others in class because of her tomboyish gestures and the body language she used during the physical activities in class. She loved ball games as well as intense exercises, and her preferred sport was soccer. She demonstrated good relationships with her male peers in class and was treated exactly like one of them. As a consequence of her physical skill in collective sports, she had a high status among the boys and was very welcome by them in the group.

Student 8 was observed during the week of school championships during which he did not take part in the competitions. While his peers participated on the main court representing their class, he stayed on an unused court playing volleyball with the girls. He was very extrovert in social interactions, but when he moved he attracted everyone's attention because of his feminine walk and gestures. Although his peers teased him, he looked quite authentic in his behavior, and demonstrated a strong self-confidence. He had good relationships with the girls, who were his best friends. Throughout the observation period he never got very close to his male classmates. He seemed to prefer being with girls rather than with another boy, who was also observed as gender divergent.

Student 9 was also observed during the school championships where he seemed quite shy. He did not mix well with his male peers. Instead of taking part in the official games, he preferred to play volleyball with the girls. In some games, the teacher asked him to participate on the official volleyball team. It was noticed that, although he made an effort to do well in the volleyball game, he was very tense when observed by the others. He did not seem at ease in PE class. In the interview he was quite shy. Nevertheless, the interviewer noticed that he had good verbal fluency and got along very well with the interviewer.

Student 10 was also in student 9's class. He was observed in the school championship games, specifically in volleyball. His gestures in the game were a little accentuated relative to his peers, with body movements unnecessary for the activity. He interacted very well with the group. In spite of his feminine corporal expression and voice, his behavior seemed quite close to the average for boys. He also had more control over his body movements, as if deliberately controlling his movements when he ran or crouched to receive the volleyball. He always talked to his classmates during the games, correcting them or making observations on their accomplishments, and he also took part in all the sporting activities. The researchers got the impression that this student constantly needed to make other members of the group aware of his presence, perhaps as a strategy to control their perception of his lack of skills. By calling for the group's attention with his corrections and his contributions
Table 1. Observed characteristics of gender-divergent children.

\begin{tabular}{lccc}
\hline Student & $\begin{array}{c}\text { 1. Motor } \\
\text { coordination } \\
\text { trouble }\end{array}$ & $\begin{array}{c}\text { 2. Androgynous } \\
\text { body movements }\end{array}$ & $\begin{array}{c}\text { 3. Seeks other-sex } \\
\text { company. }\end{array}$ \\
\hline 1 & No & Yes & Yes \\
2 & Yes & No & No \\
3 & No & Yes & No \\
4 & Yes & No & No \\
5 & No & Yes & No \\
6 & No & Yes & No \\
7 & No & Yes & Yes \\
8 & No & Yes & Yes \\
9 & No & Yes & Yes \\
10 & No & Yes & No \\
\hline
\end{tabular}

as a leader, perhaps he was trying to hide his social identity as "different".

We summarize the properties of the 10 students observed in PE classes by three criteria in Table 1: Motor coordination skills, androgynous behavior, and social preference for same or other sex company. Students 2 and 4 have motor coordination trouble, but do not have any androgynous behavior and do not prefer the company of the other sex. It seems reasonable to assume that they were originally selected because of atypical motor coordination, which gave them gestures that were "less masculine". Students 1, 7, 8, and 9 showed clear preference for associating with members of the other sex and have distinct androgynous behaviors. That is, they are far better socialized with members of the other sex. The remaining students, 3, 5, 6, and 10 have some androgynous behavior, but still prefer to associate with members of their own sex.

\section{Differences between gender divergent children and their peers}

To understand the students' preferences and their own understanding of their relationship to others, we summarized the data from the confidential and personal interviews in Tables II-V. Students 1 through 10 are the perceived gender divergent students described above. Students through 11-20 are the non-gender divergent students. Note that student 7 is the only female in the study.

Table 2 summarizes the students' responses to questions 1-5 from the methodology section. To the question, "do you know what human sexuality is?", four of the supposed gender divergent students said they knew, five still needed to learn more about it, one said that he knew very little, close to nothing. Among the controls, six said that they knew something about it, two knew just a little, and the last two knew nothing about it.

As seen in Table 2, six of the gender divergent students, but none of the control students, disliked their peers in the PE class. Thus, compared to the controls, the gender divergent students were more dissatisfied. Among the indicated students in Table 3, five had best friends of the other sex, and four had a person of the same sex as best friend. However, 
Table 2. Individual Students' Responses to the Questions: 1. Do you like your class group? 2. Who is your best mate? Is a male or a female your best classmate? 3. What do you like to play? 4. Which sports do you like the most? 5. With whom do you prefer playing, boys or girls?

\begin{tabular}{|c|c|c|c|c|c|}
\hline Student & 1. Like class & 2. Best friend & 3. Preferred play & 4. Preferred sport & 5. Play with \\
\hline 1 & No & Female & Volley ball, hide-and-seek & Volley ball & Girls \\
\hline 2 & Yes & Male & Biking, video game. & Volley ball, basket ball & Girls \\
\hline 3 & No & Male & Video game, hide-and-seek & Volley ball, basket ball, swimming & Both \\
\hline 4 & No & No friends & Tennis, chess, guessing games & Tennis, car race & Girls \\
\hline 5 & Yes & Male & Volley ball, puzzle & Swimming, volley ball & Girls \\
\hline 6 & Yes & Female & Hide-and-seek, tag, school & Swimming, jogging & Both \\
\hline 7 & Yes & Male & Soccer, volley ball, hide and seek & Basket ball, volley ball, soccer & Both \\
\hline 8 & No & Female & Skating, dancing & Skating, playing actor & Girls \\
\hline 9 & No & Female & Volley ball, hand-ball & Swimming & Girls \\
\hline 10 & No & Male & Volley ball, soccer & Karate, basket ball & Boys \\
\hline 11 & Yes & Female & Video game, soccer & Skate boarding, soccer & Boys \\
\hline 12 & Yes & Female & Hide-and-seek, soccer & Soccer, volley ball & Boys \\
\hline 13 & Yes & Male & Video game, soccer & Soccer, volley ball, basket ball & Boys \\
\hline 14 & Yes & Male & Biking & Biking, basket ball & Boys \\
\hline 15 & Yes & Male & Volley ball, basket ball & Swimming, basket ball, volley ball & Boys \\
\hline 16 & Yes & Female & Video game, cards & Soccer, hand ball & Both \\
\hline 17 & Yes & Male & Volley ball, soccer & Soccer & Boys \\
\hline 18 & Yes & Male & Volley ball, soccer & Soccer, volley ball & Boys \\
\hline 19 & Yes & Male & Volley ball & Soccer, volley ball, hand ball & Boys \\
\hline 20 & Yes & Male & Biking, video game & Volley ball, biking, diving & Boys \\
\hline
\end{tabular}

one did not have any friends at all. Among control students, three answered that they had a person of the other sex as a best friend, and seven answered that they had a person of the same sex as their best friend.

It was noticed throughout the interviews, that the indicated students who preferred another sex peer as best friend commonly justified their choice. Generally, they perceived the girls as more understanding, calmer, and friendlier than the boys. These views were offered spontaneously, since we did not ask them for any explanation for their preference. The control students did not offer similar justifications; they simply answered that a girl was their best friend. It is important to point out that the indicated students did not identify themselves with the female identity, but rather simply preferred a calmer social tie than they might find with their male peers.

Finally, Table 2 shows that the gender divergent students were more prone than the control students to choose swimming as their favorite sport.

Table 3. Sex of Closest Friends of the Participants. Summary of Data From Table 1.

\begin{tabular}{lcc}
\hline Sex of closest friends & $\begin{array}{c}\text { Gender divergent } \\
\text { students }\end{array}$ & $\begin{array}{c}\text { Randomly selected } \\
\text { students }\end{array}$ \\
\hline Opposite sex & $60 \%$ & \\
Both & $30 \%$ & $10 \%$ \\
Same sex & $10 \%$ & $90 \%$ \\
\hline
\end{tabular}

Tables 4 and 5 below expand the results from columns 3 . Preferred activities to play and 4. Preferred sports in Table 2. Due to the small sample size, we must be careful when interpreting differences in preference for one activity or the other. We do, however, observe an interesting pattern when we identify each activity by type.

Collaborative (C) activities are typically team sports that require collaborative interaction with others and where the team depends on the efforts of the individual. In this situation the good performance of the group depends directly on individual accomplishment of determined physical action or strategy.

In interactive (I) activities individuals socialize with others, who, however, do not depend on others' efforts (e.g., people can dance with others, irrespective of their dancing capabilities). Interactive sports are group activities in which individuals take part but there is no personal responsibility for the group outcome. In this situation there is more freedom and less commitment of the individual to the group result.

Solitary (S) activities are activities that are typically done alone. In solitary activities the individual does not need anybody else to participate. These could be avocations such as reading or running.

Table 4 expands on the data from column 3 in Table 2 "preferred activities to play". The gender divergent students preferred playing activities without group pressure, and they mentioned frequently "more or less" to express their preferences. Some mentioned one activity, most mentioned two, and some mentioned three. We added the contribution 
Table 4. Expanding the Data from Table 2, Column 3. Preferred play, data from Table 2.

\begin{tabular}{|c|c|c|c|}
\hline Play activity & Type & $\begin{array}{c}\text { Gender divergent } \\
\text { students }\end{array}$ & $\begin{array}{c}\text { Randomly } \\
\text { students }\end{array}$ \\
\hline Basketball & $\mathrm{C}$ & & $5 \%$ \\
\hline Biking & S & $5 \%$ & $15 \%$ \\
\hline Board games & I & $12 \%$ & $5 \%$ \\
\hline Dancing & I & $5 \%$ & \\
\hline Hand ball & $\mathrm{C}$ & $5 \%$ & \\
\hline Hide-and-seek & I & $17 \%$ & $5 \%$ \\
\hline School & I & $3 \%$ & \\
\hline Skating & S & $5 \%$ & \\
\hline Soccer & $\mathrm{C}$ & $8 \%$ & $25 \%$ \\
\hline Tag & I & $3 \%$ & \\
\hline Tennis & I & $3 \%$ & \\
\hline Video games & $S$ & $10 \%$ & $20 \%$ \\
\hline Volleyball & $\mathrm{C}$ & $23 \%$ & $25 \%$ \\
\hline Total collaborative & $\mathrm{C}$ & $36 \%$ & $55 \%$ \\
\hline Total interactive & I & $43 \%$ & $10 \%$ \\
\hline Total solitary & $\mathrm{S}$ & $20 \%$ & $35 \%$ \\
\hline
\end{tabular}

to different activities from each student by scoring $10 \%$ for a given interest, if it is the students only interest, $5 \%$ if it is one of two interests, $3.3 \%$ if it is one of three, and $0 \%$ if the student is not interested. The numbers do not sum to $100 \%$ due to rounding off.

The types of activity are arbitrary divisions of a continuum, and we can not identify an individual student's approach to a given activity. It is technically possible to be inactive "playing soccer", but this would make the person a liability to the team. It is possible to play video games in a very interactive and social setting, but it is basically a one-person-one-machine activity. We believe that our classifications of the activities are faithful to the students' intentions, but we are aware of possible individual differences.

The divergent students participated more rarely in collaborative activities than did their peers. Note that they are not "anti-social" and do not emphasize solitary activities, but they are more prone to be interactive than collaborative. That is, they do participate in social activities, but chose predominantly those where individual failure does not compromise the group. These are also less "aggressive" activities that involve less body contact and are less complex. Unfortunately, our data cannot clarify whether the divergent students shy away from aggressive activities because of possible stigmatization because they compromise the group, or because they are afraid of body contact with their peers, or because they really dislike high complexity activities where you have simultaneously to run, jump, kick, and so on. In any case, the data illustrates major differences between the groups with respect to preferences for physical activity.

Table 3 summarizes the sex of the students' closest friends of the participants, and shows again that the divergent students acknowledge a closer relationship to the other sex
Table 5. Expanding the Data from Table 2, Column 4. Preferred sport, similar to Table 3. The Numbers do not add up to $100 \%$ Due to Rounding Off.

\begin{tabular}{|c|c|c|c|}
\hline Preferred sport & Type & $\begin{array}{c}\text { Gender divergent } \\
\text { students }\end{array}$ & $\begin{array}{c}\text { Randomly } \\
\text { students }\end{array}$ \\
\hline Acting & $\mathrm{C}$ & $5 \%$ & \\
\hline Basket ball & $\mathrm{C}$ & $17 \%$ & $12 \%$ \\
\hline Biking & $S$ & & $8 \%$ \\
\hline Car Racing & I & $5 \%$ & \\
\hline Diving & $S$ & & $3 \%$ \\
\hline Hand ball & $\mathrm{C}$ & & $8 \%$ \\
\hline Jogging & $S$ & $5 \%$ & \\
\hline Karate & I & $5 \%$ & \\
\hline Skating & $S$ & $5 \%$ & $5 \%$ \\
\hline Soccer & $\mathrm{C}$ & $3 \%$ & $37 \%$ \\
\hline Swimming & $S$ & $23 \%$ & $3 \%$ \\
\hline Tennis & I & $5 \%$ & \\
\hline Volleyball & $\mathrm{C}$ & $27 \%$ & $23 \%$ \\
\hline Total collaborative & $\mathrm{C}$ & $52 \%$ & $80 \%$ \\
\hline Total interactive & I & $15 \%$ & $0 \%$ \\
\hline Total solitary & $S$ & $33 \%$ & $19 \%$ \\
\hline
\end{tabular}

than do their peers. Compare this to Table 1, where four of the indicated students were observed to associate preferably with members of the other gender. None of the controls showed this behavior, which suggests that the divergent students in action as well as by their own statements are much closer to members of the other sex than their same sex peers.

It is important to note that the students indicated as gender divergent by the teachers differ markedly from their peers in several ways. Some of the differences are observable; others are expressed by the individuals themselves. The differences include motor coordination, social interaction, and personal preferences. It is equally important to emphasize that these students do not "suffer" from a treatable condition and that the teacher's original assessment of gender divergence is far from infallible.

Two of the divergent students ( 2 and 4 ) have motor coordination problems that border on a slight disability, but do not show any androgynous behavior and only one of the students has a preference for friends of the other sex. Except for a possible prejudice caused by their motor coordination problems, they are hardly more "effeminate" than their male peers (exception for the girl). They seem to be marginalized due to their motor coordination rather than any kind of androgynous behavior. That is, a cursory review even by individuals who know the students well may identify them as "different" but not necessarily distinguish between gender divergence and motor coordination problems.

\section{Teachers' view of gender identity and roles}

The interview with PE teachers began with personal and professional questions. Translated quotes are placed in quotation marks. In order to maintain their confidentiality, 
we interviewed the teachers outside of their work place and identify them by numbers 1 through 6 .

We asked the teachers about their past professional experience with presumed gender divergent students and how they treat them in class. Teacher 1 , who at the time of the study had other gender divergent students, said, "I try to give them moral support and socialize them". Teacher 3, who also had previous experience, said "I try to be open, I try to break the barriers, and I request some respect from the group". Teacher 5 managed situations by "giving the same attention I give the others; I don't allow the group to tease him/her, and I try to socialize them". Teacher 6, who had one previous experience, said, "it was difficult to teach PE class with this kind of trouble; girls didn't accept him in class, but the student didn't want to take classes with boys. He used to be a good student, and I tried to do all I could during the classes, as you know feelings spoke louder inside me and I followed them, since professionally I was not prepared for it".

We also asked how they define this different "behavior" among the indicated students. All said something like "the difference lies in their way of speaking, walking, and dressing, and in having only one friend with whom they play most of the time, seeking isolation from other peers, and some kind of protection from the teachers". None of the interviewees possessed any knowledge of this issue; they just noticed the conflicts caused by the intolerance in relation to these "different" students.

We asked for their views on homosexuality to gauge their views on gender and sexual orientation. Teacher 1 said, "I think it is improper behavior, it is strange to me." Teacher 2 said, "I think it is a kind of disease, a deviation, something badly resolved; it should be treated." Teacher 3 simply stated: "I suppose it must be related to a hormonal deficiency; I don't believe that anyone can change his or her personality so much just by choice, I believe this is biological." Teacher 4: "I think they must be battling to learn how to be a man; on the other hand, I believe it could be a family problem or a genetic influence. I am confused. It shocks me when I see it". In summary, it appears that these teachers see homosexuality as something deviant from the natural order. Teacher 5 said, "I believe there is just too much freedom in today's education, for instance, these collective showers or the grandparents' bad influences. But I also believe they ought to be respected; they are part of society". Teacher 6 said, "I think it could be either too much freedom or simply personal choice; I don't know, I have very little knowledge about the subject. It is different when they perform it as a form of art like drag-queens, in a professional way". Teachers 5 and 6 demonstrate a little more willingness to understand and accept sexual differences. We asked the teachers how they treat boys and girls in class, particularly whether they treat them differently. Five of them affirmed that they treat boys and girls differently and are more severe with boys. They said they were trying to fulfill the boys' needs, as boys demand more effort in class. They claimed that the male students like the pressure of more rigid treatment.

The treatment of the girls is illustrated by this view: "for girls the treatment is slack; I concentrate more on the tender aspects; the girls are more malleable, more polite".
In summary, they try to apply a more feminine and delicate treatment to girls because according to one of the female teachers, the girls who are treated like boys become tomboys. Only one of the teachers tried to offer the same treatment to both genders in classes.

We asked for their views on gender and body motor performance orientation - that is what are the differences between boys and girls? They agreed that boys are more agile, more dynamic, more physically skilled and stronger. They maintained that boys more easily execute complex movements, have greater space perception, and greater ability to assimilate information. According to the teachers, girls are slower, less coordinated, more delicate and weaker. One of the teachers did admit that there is possibly no difference between the two genders: "I think they can in some way be similar or even the other way around; it depends on what you want to compare and when you compare". When we asked the teachers what they thought the reasons could be for the differences mentioned above, they all emphasized how children are educated: "Boys have more freedom, girls usually stay inside the house". But in relation to their own natures, they responded by saying "... boys are physically stronger."

We asked for their preference for teaching male or female PE classes, and all three female interviewees preferred to give classes to female students. Of the three male interviewees, one preferred to give classes to boys, one had no preference, and one preferred girls.

The teachers saw gender differences as a major issue in coeducational physical education classes. Teachers 4, 5, and 6 pointed out many differences between boys and girls that related to body coordination abilities. They also agreed that the boys stood out relative to the girls in activities that demand more strength and agility since they are stronger and have more will to learn; whereas the girls are slower, more frail, and unwilling to practice physical activities. Due to this perception we can understand why they identified students 2 and 4 as gender divergent.

The main difficulty encountered when working with gender divergent students, according to the teachers, was what to do regarding the difficulty the students had in interacting with their peers and their visible preference for activities of the other sex.

\section{Discussion}

Some of the designated students had distinct qualities, that is, they expressed a preference for association with the other sex and a dislike of activities of their own sex peers. They displayed some androgynous behavior and participated in activities of the other sex that identify them as gender divergent. These designated students, identified as 1, 3, 5, 6, $7,8,9$, and 10 , show some divergences from their own sex, and at least one characteristic typical of the other sex. Other students, identified as 2 and 4, do not show the same gender divergence, but do have notable, unusual motor patterns. That is, the original designated group of 10 students includes some with gender divergent aspects, and some with slight motor handicaps.

The indicated students include only one gender divergent girl, student 7. She has the same properties as the gender 
divergent boys; a preference for associating with members of the other sex, participating in sports popular with other gender, etc. The data are insufficient to conclude that gender divergent girls have the same social characteristics as gender divergent boys, but at least we have no indication to the contrary. We note that the girl in this study was accepted as an equal participant by her male peers, and was in many respects less marginalized than many of the gender divergent boys. That girls with masculine attributes may enjoy higher status than boys with feminine attributes may help explain the findings by Donelson and Gullahorn (1977) and Hemmer and Kleiber (1981) that tomboyism, although quite common, is less recognized as abnormal. The relative paucity of tomboys in this study may be artifact of the emic sampling strategy.

This study suggests that PE teachers confuse "genderdivergence" with uncoordinated motor behaviors. This may be because PE classes emphasize motor abilities and coordination and PE teachers may pay particular attention to these characteristics and use them (wrongly) as a criterion for gender divergence. In our interviews with the teachers, we asked how they recognized gender-divergent students and all said something like "the difference lies in their way of speaking, walking and dressing,...". Physical appearance and motor behavior play an important role for the PE teacher's classification of students.

Although motor behaviors may not be the best way to identify gender-divergent children, there are gender differences in motor behaviors. Thomas and French (1985) documented gender differences prior to puberty in 15 of 20 physical tasks. The main difference appears to be that boys become involved in more competitive games than girls and generally participate in games that last longer. There are known differences between genders in this age group in terms of motor patterns and individuals that manifest the motor pattern of the other gender may be perceived as gender divergent. In this study the gender-divergent children did manifest more androgynous motor behaviors, but their motor coordination was similar to other children, suggesting that PE teachers confuse androgynous motor behavior with lack of coordination.

Although gender stereotyping is well documented in schools and male children with conflictive sexual identity have been thoroughly studied during the past decade, there is not much discussion about their implications for the educational process in our traditional schools. In order to include these "excluded" children in PE classes (and perhaps in other school activities as well), we need more studies clarifying the differences in order to suggest alternate physical activities for PE classes in which these excluded children might be better able to participate. This requires studies of alternative physical activities that contemplate and value differences among children motor orientation. Cardoso (1994b, 2002, 2005) suggested that we should consider "motor orientation" as a good concept to analyze different motor abilities across sex, gender and sexual orientation. Both those students who lack physical coordination and those who show more androgynous motor behaviors need more opportunities in class to show their motor abilities that could be more orientated to dance, skating, gymnastics, etc.

\section{References}

Bates, J., Bentler, P. \& Thompson, S. (1979). Gender deviant boys compared with normal and clinical control boys. Journal of Abnormal Child Psychology, 7, 243-259.

Blanchard, R., Dickey, R. \& Jones, C. (1995). Comparison of height and weight in homosexual versus non-homosexual male gender dysphorics. Archives of Sexual Behavior, 24, 543-554.

Cardoso, F. L. (1994a). O gênero e o movimento humano. Revista Brasileira de Ciências do Esporte, 15, 265-268.

Cardoso, F. L. (1994b). Orientação sexual masculina em uma comunidade pesqueira. Dissertação de Mestrado, Universidade de Santa Catarina, Florianópolis.

Cardoso, F. L. (2002). "Fishermen"-Masculinity and sexuality in a Brazilian fishing community. Sexuality and Culture, 6, 45-72.

Cardoso, F. L. (2005). Cultural universals and differences in male homosexuality: The case of a Brazilian fishing village. Archives of Sexual Behavior, 34 (1), 105-111.

Davenport, C. (1986). A follow-up study of 10 feminine boys. Archives of Sexual Behavior, 15, 511-517.

Donelson, E. \& Gullahorn, J. (1977). Women - A psychological perspective. New York: Willey.

Duda, J. \& Alison, M. (1990). Cross-cultural analysis in exercise and sport psychology. Journal of Sport and Exercise Psychology, 12, 114-131.

Frasher, R. \& Walker, A. (1972). Sex roles in early reading textbooks. Teacher, 25, 741-749.

Green, R. (1974). Sexual identity conflict in children and adults. New York: Basic Books and Viking/Penguin; London: Gerald Duckworth.

Green, R. (1976). One-hundred ten feminine and masculine boys: Behavioral contrasts and demographic similarities. Archives of Sexual Behavior, 5, 425-446.

Green, R. (1987). The sissy boy syndrome and the development of homosexuality. New Haven: Yale University Press.

Green, R., Neuberg, D. \& Finch, S. (1983). Sex-typed motor behaviors of "feminine" boys, conventionally masculine boys, and conventionally feminine girls. Sex Roles, 9, 571-579.

Green, R., Williams, K. \& Goodman, M. (1985). Masculine or feminine gender identity in boys: developmental differences between two diverse family groups. Sex Roles, 12, 1155-1162.

Grellert, E., Newcomb, M. \& Bentler P. (1982). Childhood play activities of boys and girl's homosexual and heterosexuals. Archives of Sexual Behavior, 11, 451-478.

Harris, M. (1968). A natureza das coisas culturais. Rio de Janeiro: Civilização Brasileira.

Hemmer, J. \& Kleiber, D. (1981). Tomboys and sissies: Androgynous children? Sex Roles, 7, 1205-1212.

Hockenberry, L. \& Billingham, E. (1987). Sexual orientation and boyhood gender conformity: development of the boyhood gender conformity scale (BGCS). Archives of sexual behavior, $16,475-487$.

Jackson, P. (1968). Life in classrooms. New York: Holt, Rinehart \&Winston.

Levy, B. \& Stacey, J. (1973). Sexism in the elementary school: a backward and forward look. Phi Delta Kappan, 55, 105-109.

Lynch, J. (1975). Equal opportunity or lip service? Sex-role stereotyping in the schools. Elementary School Journal, 76, 20-23. 
Reha, R. \& Nappi, A. (1975). Are your sex stereotypes showing? Elementary School Journal, 76, 70-74.

Romero, E. (1994). A Educação Física a serviço da ideologia sexista. Revista do Colégio Brasileiro de Ciências do Esporte, 15, 226-234.

Saario, T., Jacklin, C. \& Tittle, C. (1973) Sex-role stereotyping in the public schools. Harvard Educational Review, 43, 386-415.

Thomas, J. \& French, K. (1985). Gender differences across age in motor performance: a meta-analysis. Physiological Bulletin, 98, 260-282.

Wakefield, J., Sasek, J., Friedman, A. \& Bowden, J. (1976). Androgyny and other measures of masculinity-femininity. Journal of Consulting and Clinical Psychology, 44, 766-770.

Whitam, F. (1983). Culturally invariable properties of male homosexuality: tentative conclusions from cross-cultural research. Archives of sexual behavior, 12, 207- 226.

Whitam, F. (1991). Childhood cross-gender behavior of homosexual females in Brazil, Peru, the Philippines, and the United States. Archives of sexual behavior, 20, 151-170.

Whitam, F. \& Mathy, R. (1986). Male homosexuality in fours
Societies: Brazil, Guatemala, the Philippines, and the United States. New York: Plaeger.

Zucker, K. (1990). Gender identity disorders in children: clinical descriptions and natural history. Em R. Blanchard \& B. Steiner (Orgs.), Clinical management of gender identity disorders in children and adults (p. 1-23). Washington: American Psychiatric Press.

Zucker, K. \& Bailey, M. (1995). Childhood sex-typed behavior and sexual orientation: a conceptual analysis and quantitative review. Developmental Psychology, 31, 43-55.

Recebido em 01.02.2005

Primeira decisão editorial em 04.08.2005

Versão final em 11.11.2005

Aceito em 26.11.2005 